\title{
SENSORIMOTOR BEHAVIORAL TESTS FOR USE IN A JUVENILE RAT MODEL OF TRAUMATIC BRAIN INJURY: ASSESSMENT OF SEX DIFFERENCES
}

\author{
Kristin L. Russell ${ }^{\mathrm{a}}$, Katrina M. Kutchko ${ }^{\mathrm{a}}$, Stephen C. Fowler ${ }^{\mathrm{b}}$, Nancy E. J. Berman ${ }^{\mathrm{c}}$, and \\ Beth Levant $^{a}$ \\ Kristin L. Russell: krussel@kumc.edu; Katrina M. Kutchko: katrina.kutchko@coloradocollege.edu; Stephen C. Fowler: \\ scfowler@ku.edu; Nancy E. J. Berman: nberman@kumc.edu; Beth Levant: blevant@kumc.edu \\ a Department of Pharmacology, Toxicology, and Therapeutics, University of Kansas Medical \\ Center, 3901 Rainbow Blvd., Kansas City, KS 66160 USA \\ b Department of Pharmacology \& Toxicology, University of Kansas, 5036 Mallot Hall, Lawrence, \\ KS 66045 USA \\ c Department of Anatomy \& Cell Biology, University of Kansas Medical Center, 3901 Rainbow \\ Blvd., Kansas City, KS 66160 USA
}

\begin{abstract}
Modeling juvenile traumatic brain injury (TBI) in rodents presents several unique challenges compared to adult TBI, one of which is selecting appropriate sensorimotor behavioral tasks that enable the assessment of the extent of injury and recovery over time in developing animals. To address this challenge, we performed a comparison of common sensorimotor tests in Long-Evans rats of various sizes and developmental stages (postnatal days 16-45, 35-190 g). Tests were compared and selected for their developmental appropriateness, scalability for growth, pre-training requirements, and throughput capability. Sex differences in response to TBI were also assessed. Grid walk, automated gait analysis, rotarod, beam walk, spontaneous forelimb elevation test, and measurement of motor activity using the force-plate actometer were evaluated. Grid walk, gait analysis, and rotarod failed to meet one or more of the evaluation criteria. Beam walk, spontaneous forelimb elevation test, and measurement of motor activity using the force-plate actometer satisfied all criteria and were capable of detecting motor abnormalities in rats subjected to controlled cortical impact on postnatal day 17. No sex differences were detected in the acute effects of TBI or functional recovery during the 28 days after injury using these tests. This demonstrates the utility of these tests for the evaluation of sensorimotor function in studies using rat models of pediatric TBI, and suggest that pre-pubertal males and females respond similarly to TBI with respect to sensorimotor outcomes.
\end{abstract}

\section{Keywords}

Traumatic brain injury; juvenile; forelimb; hindlimb; actometer; beam walk; controlled cortical impact; sensorimotor

\footnotetext{
(C) 2011 Elsevier B.V. All rights reserved.

Corresponding author: Beth Levant, Ph.D., Department of Pharmacology, University of Kansas Medical Center, Mail Stop 1018, 3901 Rainbow Blvd., Kansas City, KS 66160, Phone: 1 (913) 588-7527, FAX: 1 (913) 588-7501, blevant@kumc.edu.

Publisher's Disclaimer: This is a PDF file of an unedited manuscript that has been accepted for publication. As a service to our customers we are providing this early version of the manuscript. The manuscript will undergo copyediting, typesetting, and review of the resulting proof before it is published in its final citable form. Please note that during the production process errors may be discovered which could affect the content, and all legal disclaimers that apply to the journal pertain.
} 


\section{Introduction}

More than 1.7 million traumatic brain injuries (TBI) are sustained each year in the United States with a large portion of them occurring in children aged 0 to 4 years old (Faul et al., 2010). Despite the greater neuronal plasticity of the immature brain, young children appear to be more adversely affected by the initial injury and have the highest mortality rate of all age groups (Giza and Prins, 2006; Luerssen et al., 1988; Prins and Hovda, 2003). Long-term consequences of TBI include sensorimotor deficits and difficulties with life activities such as long-term memory, attention, language, problem solving, and managing stress and emotions, which can later impair school and job performance (Davis and Dean, 2010; Ginstfeldt and Emanuelson, 2010; Horton et al., 2010; Lajiness-O'Neill et al., 2010; Noggle and Pierson, 2010; Sullivan and Riccio, 2010; Ylvisaker et al., 2001). TBI can also lead to long-term adverse effects such as epilepsy and increased risk for aging-associated diseases such as Alzheimer's and Parkinson's (National Institute of Neurologic Disorders and Stroke, 2002; Ylvisaker et al., 2001). Thus, there is a critical need to develop effective interventions for juvenile TBI, which requires appropriate animals models.

Testing the effects of juvenile brain injuries in animal models, particularly assessing recovery of function after injury, presents several challenges that are not encountered in adult models. For example, age-matched controls must be used to account for developmental changes over the course of testing (Prins and Hovda, 2003). Also, many common methods for measuring recovery in adult TBI models are unsuitable for use in a juvenile model due to their inability to scale for the rapid growth of the rats during the juvenile and adolescent periods and the necessity for extensive training prior to injury when the rats are quite immature. To address these challenges of studying functional outcomes in an animal model of juvenile TBI, we tested the suitability of six sensorimotor behavioral tests. The animal model is a controlled cortical impact (CCI) injury in 17-day old rats, a developmental time point roughly similar to the toddler period in humans with regard to motor function that has been used in a number of previous studies (Adelson, 1999; Altman and Sudarshan, 1975; Prins and Hovda, 2003; Westerga and Gramsbergen, 1990). The tests examined included the grid walk, accelerating rotarod, beam walk, and the spontaneous forelimb elevation test, which have been used in a variety of TBI studies in adult rodents (e.g., Baskin et al., 2003; Chen et al., 2008; Hamm, 2001; Hamm et al., 1994; Onyszchuk et al., 2007). We also examined the automated gait analysis system, which has been used to assess motor deficits after spinal cord injury (Ek et al., 2010; Springer et al., 2010), and the force-plate actometer, a device typically used to measure locomotion and related behaviors (Fowler et al., 2001). Tests were evaluated based on their pre-training requirements, ability to scale for the growth of the rat over time, and whether the task was developmentally appropriate for 17-45-day old rats. Tests were also assessed for throughput capacity. We will show that three tests met our criteria and detected sensorimotor deficits in a contusion model of TBI using juvenile rats. Furthermore, we will show that juvenile male and female rats exhibit similar sensorimotor deficits following TBI.

\section{Materials and methods}

All experiments were conducted in accordance with the NIH Guide for the Care and Use of Laboratory Animals and were approved by the University of Kansas Medical Center Institutional Animal Care and Use Committee.

\subsection{Animals and husbandry}

Long-Evans rats were housed in a temperature- and humidity-controlled facility with a 1410 hour light-dark cycle (on at 06:00 h) with ad libitum access to water and Teklad 
Laboratory Rodent Diet \#8604 (Harlan Laboratories, Inc., Indianapolis, IN). Breeding stock (females 75-85 days; male proven breeders; Harlan Laboratories, Inc. Indianapolis, IN) were obtained a minimum of 5 days prior to the beginning of the experiment and were handled regularly. Mated females were singly housed. Litters were culled to eight pups (four females/four males) on postnatal day (PND) 1. Pups used in the TBI experiments received either a CCI injury or sham surgery on PND 17 and were returned to the dam until weaning. Pups were weaned on PND 20 and then housed in groups of two to four, TBI and shaminjured together, for the remainder of the study.

\subsection{Procedures}

With the anticipation that the sensorimotor tests would be used to assess the effects of a TBI occurring on PND 17 for at least 28 days after injury, the initial evaluation of the sensorimotor tests examined the use of each procedure with rats ranging in age from as early as PND 14 (allowing for as many as three days of pre-training, depending on the test) through PND 45. Tests were evaluated based on four criteria: the necessity for pre-training to learn the task before injury, ability to scale the test to accommodate animals of varying sizes, whether the task was developmentally appropriate for rats at all of the relevant ages, and the throughput capacity including the labor required to analyze the data. Scalability was determined empirically by testing the ability of rats of each age group to perform each test on each available size of apparatus.

All testing occurred between 09:00 and 12:00 $\mathrm{h}$ in a brightly lit room specifically reserved for rodent behavioral testing. Animals were brought to the behavior room in their home cages and allowed to acclimate for approximately $15 \mathrm{~min}$ before beginning testing. Each test was performed by each animal on each day of testing.

Once suitable tests were identified, a second cohort of rats was used to assess the ability of each test to detect a motor deficit after TBI and during the short-to-midterm recovery period using a repeated measures design. Sex differences in response to TBI were also evaluated. For those experiments, male and female pups ( $\mathrm{n}=12-15$ /group) were subjected to TBI using CCI or sham surgery on PND 17. Pups were assigned to treatment groups so that each group included pups from 7 litters and no group contained more than 3 pups from any litter.

2.2.1. Controlled cortical impact-Rats were anesthetized with isoflurane (induction, 3.0\%; maintenance, 2.0\%) and stabilized in a Cunningham stereotaxic frame (Stoelting, Wood Dale, IN). The scalp was retracted, and a $4 \times 4 \mathrm{~mm}$ craniotomy was performed with a burr drill, lateral (right side) to the mid-sagittal suture, with the center at the following coordinates: $\mathrm{AP}=0, \mathrm{ML}=2.5$ from bregma. The burr and surface of the skull were cooled with periodic application of room temperature saline. The impactor device consisted of a linear motor device (the impactor) with a stainless steel tip, power supply and microprocessor controller (Linmot, Zurich, Switzerland), a Plexiglas table, and a stand for the linear motor device made with an adjustable manipulator (Kopf, Tujunga, CA), which allowed precise positioning of the impactor (Bilgen, 2005; Narayana et al., 2004; Onyszchuk et al., 2007). The impactor was outfitted with a $3.0 \mathrm{~mm}$-diameter tip with a flat face and slightly rounded edge. The position of the impactor and tip was carefully adjusted to be centered within the craniotomy and tangential to the dural surface. The impactor tip was lowered in $0.05 \mathrm{~mm}$ increments until the tip just contacted the dura (by visual inspection under surgical microscope at 40x magnification). The cortical impact was initiated through the instrument's graphical user interface with the following parameters: $3.0 \mathrm{~mm}$ depth, 1.5 $\mathrm{m} / \mathrm{sec}$ strike velocity, $300 \mathrm{msec}$ contact time. The contact area included motor (M1, M2) and sensory (S1FL, S1HL) cortical areas (Paxinos and Watson, 1986; Sherwood and Timiras, 1970). After the impact, the scalp was closed with 6-0 silk suture, anesthesia was 
discontinued, and the animal temperature was maintained at $37^{\circ} \mathrm{C}$ until recovery of locomotion. Sham-injured rats received the scalp incision only, but no craniotomy or impact from the CCI device. This sham procedure was used because sham procedures involving the use of a trephine or drill to produce craniotomy have been shown to cause brain injury distinct from that caused by impact resulting in an experimental confound (Cole et al., 2011). All rats received $0.05 \mathrm{mg} / \mathrm{kg}$ of buprenorphine approximately one hour after surgery and again 24 hours after surgery, after day 1 behavioral testing was completed.

2.2.2. Grid walk—Rats were placed on an elevated wire grid $(46 \times 92 \mathrm{~cm})$, with $2.5 \times 2.5$ $\mathrm{cm}$ square holes and allowed to walk for five min while being videotaped from below, as previously described (Onyszchuk et al., 2007). Three 5-min sessions were performed for each rat on each test day, with the rat spending at least $5 \mathrm{~min}$ in the home cage between sessions. Videos were later analyzed for total walking time, number of steps taken, and the number of foot faults for each foot. Foot faults were defined as an instance where the animal attempted to place weight on a foot, which then passed completely through the plane of the wire grid. Foot fault data were normalized to the total time spent walking to account for differences in the degree of locomotion seen in different trials, and are expressed as foot faults per min of walking.

2.2.3. Automated gait analysis-Gait was assessed using a Digigait imaging system (Mouse specifics, Inc.). Rats were placed in the lighted Plexiglas chamber situated on a motorized transparent treadmill. Paw placement was captured from the ventral aspect using a high-speed digital video camera (150 frames $\left./ \mathrm{sec}, 5000 \mathrm{pixels} / \mathrm{cm}^{2}\right)$ mounted under the treadmill. Five-sec recordings were made of the rats walking between 5 and $10 \mathrm{~cm} / \mathrm{sec}$ and were analyzed using Digigait analysis software to analyze more than 25 parameters of gait.

2.2.4. Rotarod-An accelerating mouse-sized rotarod (Med Associates ENV-575M) was used in accordance with the methods of Hamm et al. (1994). Rats were trained daily for three days prior to injury. Rod speed accelerated from 4-40 RPM over the course of 5 min. Six min was the maximum time allowed on the rotarod. Rats were tested three times on each testing day, with a minimum of $5 \mathrm{~min}$ of rest in the home cage between trials.

2.2.5. Beam walk-Rats were tested for their ability to traverse a $75 \mathrm{~cm}$-long wooden dowel elevated $30 \mathrm{~cm}$ and ending in a dark goal box. Two training sessions were performed on PND 16 and PND 17 prior to surgery, which were sufficient for all rats to meet the preinjury performance criterion of being able to complete two traverses of the full length of the rod. Beams of increasing diameter were used to accommodate the growth of the rats over the course of testing. Beam sizes were selected based on the criteria that the diameter was sufficiently large that the rat was able to walk the length of the beam, but not large enough that the rat could lie on the beam and crawl. A $15 \mathrm{~mm}$ diameter beam was used for PND 16 and 17 pre-surgery training and testing on days 1 and 7 after surgery. An $18 \mathrm{~mm}$ diameter beam was used for testing 14 days after surgery, and a $21 \mathrm{~mm}$ diameter beam was used for testing 21 and 28 days after surgery. On testing days, rats traversed the beam three times. Test sessions were video-taped. The videos were scored for ipsilateral and contralateral foot slips, time required to reach the goal box, and total number of steps taken by the right (uninjured) hind foot. Data are reported as the percent of contralateral foot slips [i.e., (contralateral foot slips/total ipsilateral foot steps) $\times 100$ ], to control for the decreasing number of steps needed to traverse the beam as the rats grow, and average speed $(\mathrm{cm} / \mathrm{sec})$.

2.2.6. Spontaneous forelimb elevation (cylinder) test-Rats were placed in a glass cylinder (standard laboratory beaker or cylindrical vase [Living Bright, Inc.]) scaled to the size of the rat so that the cylinder diameter was roughly $4 \mathrm{~cm}$ greater than the length of the 
rat from nose to hind quarters, thus providing ample room for the rat to turn, but also minimizing horizontal exploration of the cylinder ( $12 \mathrm{~cm}$ diameter for PND 16 pre-injury measurements and measurements 1 day after surgery, $15 \mathrm{~cm}$ for 7 days after surgery, and an $18 \mathrm{~cm}$ for 14, 21, and 28 days after surgery). Rats were observed for spontaneous rearings during a single 5-min observation session. The number of wall rearings using both left and right, right only, or left only forelimbs were recorded. A measurement performed on the day prior to TBI surgery, was taken to control for pre-injury limb preference. The laterality score was computed as follows: (number of right only - number of left only)/(number of right only + number of left only + number of both together) (Schallert et al., 2000).

2.2.7. Assessment of motor activity using the force-plate actometer-Rats were placed in the force-plate actometer chambers $(42 \times 28 \mathrm{~cm})$ enclosed in a dark, soundattenuating cabinet. Behavior was recorded for $20 \mathrm{~min}$ in 2-min time bins. A small wallmounted fan in each cabinet provided background noise and air circulation. Data were analyzed for total distance traveled, number of low mobility bouts ( $\geq 10 \mathrm{sec}$ within a $20-\mathrm{mm}$ radius), and low mobility distance (distance traveled during bouts of low mobility) as previously described by Fowler et al. (2001), and turning bias (see below).

To determine turning bias, the center of force coordinates of the rats' movements were referenced to the geometric center of the floor on which the animals moved, and vector algebra was used to calculate angular direction of movements (degrees) relative to the floor geometric center every $0.01 \mathrm{sec}$. Movements in a counter-clockwise direction (turning to the left) were coded with a positive algebraic sign (a convention of trigonometry) while movements in the clockwise direction received a negative algebraic sign. These signed values were summed algebraically as session time advanced to yield the net directional rotations. The method is analogous to using a bidirectional mechanical counter attached to a rat with a tether such that turns in one direction count up (add) and turns in the opposite direction count down (subtract). Zero turning bias, therefore, is reflected by zero counts at the end of the recording session.

All data were analyzed for the entire 20-min session on each testing day after injury. Data for distance traveled, bouts of low mobility, and low mobility distance were further analyzed in 2-min time bins on day 1 after injury.

\subsection{Statistical analysis}

Data from tests found suitable for use with the rat model of juvenile TBI were analyzed for effects of injury (TBI or sham-injured) and sex (male or female) by repeated measures ANOVA with factors of TBI, sex, and day after injury (1-28 days after injury, repeated measure). Force-plate actometer data were also analyzed for effects across the observation session by 3-way ANOVA with factors TBI, sex, and time bin (repeated measure). Post hoc comparisons were made using 1-way ANOVA and the Fisher's Least Significant Difference test. A significant difference was assumed if $\mathrm{P}<0.05$.

\section{Results}

\subsection{Evaluation of sensorimotor tests for use in a juvenile rat model of TBI}

Six tests of sensorimotor function were evaluated for their developmental appropriateness, scalability for growth, pre-training requirements, and throughput capability. Results are summarized in table 1 .

The grid walk test required no pre-training prior to injury, and was easily performed by rats of ages ranging from PND 14-45. However, the test was not readily scalable to 
accommodate growth over time. While scaling could be accomplished by constructing multiple apparatus with appropriately-sized grid, the limited number of sizes of wire mesh would compromise the ability for the test to be of equal difficulty for all ages. Throughput was limited due to the necessity of performing multiple runs for each animal, as well as the time-consuming analysis of the videos. Because of the scalability issues, limited throughput, and high labor commitment, we deemed this test unsuitable for use in rats subjected to CCI on postnatal day 17 .

The automated gait analysis proved usable, but not ideal, with rats of ages of interest. All ages appeared to be capable of walking on the treadmill. The test required no pre-training prior to injury. However, the rats were generally disinclined to run or walk on the treadmill. In addition, as the male rats went through puberty, contact of the testes with the treadmill generated aberrant data signals that were misinterpreted by the analysis software and required time-consuming correction of the tracings. These issues led to the conclusion that this test was not suitable for studying long-term recovery in the PND 17 TBI model.

The accelerating rotarod had relatively high throughput, due to having short trial durations and automated data collection. However, the test required a minimum of three days of training prior to injury. In the juvenile rat model, this necessitated that training begin on PND 14. At this point in development, which is roughly when the pup's eyes open, the rats proved to be insufficiently coordinated to learn this task. Scalability also proved to be a problem. Notably, commercial accelerating rotarods are available only in two sizes designed for adult mice or adult rats. The lack of intermediate sizes makes it difficult to accommodate the growth of juvenile rats over the course of testing without also changing the task for rats of different ages. Thus, the rotarod test was also eliminated for use with the juvenile TBI model.

The beam walk test required only minimal pre-training prior to injury in order for the rats learn to traverse the beam. Two brief training sessions prior to injury, requiring about 15 min per rat, were adequate for the pups to meet the criterion of being able to traverse the full length of the beam, and the second session could be done on the day of injury prior to surgery. This test was easily scalable for rats of different sizes by using beams with increasingly larger diameters. Rats as young as PND 16 were capable of completing the test. Time required to test each animal was minimal; thus, experimental throughput was acceptable. Analysis of video-tapes was comparatively labor intensive, but was less so than for the grid walk test. Thus, the beam walk met all criteria for use with the PND 17 rat model of TBI and was further evaluated for its ability to detect deficits after injury.

The spontaneous forelimb elevation test, or the cylinder test, required no pre-training, though a test session prior to injury is required to determine if any baseline limb preference exists. This test was easily scalable by using cylinders of varying diameters and wall heights. In addition, the test was readily performed by rats of any of the ages tested. Throughput was relatively high. Thus, the spontaneous forelimb elevation test met all the criteria for use with the PND 17 rat model of TBI and was further evaluated for its ability to detect deficits after injury.

Assessment of motor activity using the force-plate actometer required no pre-training prior to injury, had no developmental limitations, and had a very high throughput due to automated data collection. The actometer chamber accommodated rats of all of the ages of interest, though the relationship between the size of the rat and the size of the chamber changed as the rat grows. Accordingly, the force-plate actometer was also assessed for its ability to detect a deficit after injury. 


\subsection{Effects of $T B I$ in juvenile rats and assessment of sex differences}

3.2.1. Beam walk-With respect to percent of contralateral foot slips (fig. 1A), three-way ANOVA indicated a main effects of injury $\left(\mathrm{F}_{1,48}=89.35, \mathrm{P}<0.001\right)$ and day after TBI $\left(\mathrm{F}_{4,192}=27.72, \mathrm{P}<0.001\right)$, and an interaction of injury with day after injury $\left(\mathrm{F}_{4,192}=5.29\right.$, $\mathrm{P}<0.001$ ). Post hoc analysis indicated that rats with TBI exhibited an increased percentage of contralateral foot slips while traversing the beam compared to sham-injured rats on each day of testing. In addition, while all rats showed improvement in performance between PND 17 and PND 45, those with TBI exhibited a more pronounced improvement in the first 14 days after injury. There was no main effect of sex, or interaction of sex with the other parameters.

Traverse speed exhibited main effects of injury $\left(\mathrm{F}_{1,48}=5.01, \mathrm{P}<0.05\right)$ and day after injury $\left(\mathrm{F}_{4,192}=46.63, \mathrm{P}<0.001\right)$, but no interaction of injury with day after injury (fig. $\left.1 \mathrm{~B}\right)$. This indicated that rats with TBI traversed the beam more slowly than sham-injured rats and that all rats showed improvement in performance across test sessions. There was no main effect of sex, or interaction of sex with the other parameters.

3.2.2. Spontaneous Forelimb Elevation Test-No differences in laterality were detected prior to injury. After injury, three-way ANOVA revealed only a main effect of injury $\left(\mathrm{F}_{1,50}=28.05, \mathrm{P}<0.001\right)$ indicating that rats with $\mathrm{TBI}$ exhibited greater tendency to use the forelimb ipsilateral to the injury compared to sham-injured rats on all days after injury (fig. 2). There was no effect of sex, or interaction of sex with the other parameters.

3.2.3. Assessment of motor activity using the force-plate actometer-Distance traveled exhibited a main effect of day after injury $\left(\mathrm{F}_{4,200}=40.34, \mathrm{P}<0.001\right)$ such that rats exhibited less locomotor activity with increasing age (fig. 3A). There were no main effects of injury or sex. An interaction of day with sex was detected $\left(\mathrm{F}_{4,200}=2.92, \mathrm{P}<0.05\right)$, but proved non-significant after post-hoc analysis.

Bouts of low mobility ( $\geq 10 \mathrm{sec}$ spent within a 20 -mm radius) (fig. 3B), and low mobility distance (the distance traveled during bouts of low mobility) (fig. 3C) exhibited significant main effects of injury $\left(\mathrm{F}_{1,50}=13.48, \mathrm{P}=0.001\right.$ and $\mathrm{F}_{1,50}=22.50, \mathrm{P}<0.001$, respectively), day $\left(\mathrm{F}_{4,200}=51.33, \mathrm{P}<0.001\right.$ and $\mathrm{F}_{4,200}=165.37, \mathrm{P}<0.001$, respectively $)$ and interactions of injury with day after injury $\left(\mathrm{F}_{4,200}=9.16, \mathrm{P}<0.001\right.$ and $\mathrm{F}_{4,200}=24.97, \mathrm{P}<0.001$, respectively). Post hoc analysis indicated that rats with TBI had fewer low mobility bouts on days 1, 7 and 14 after injury and lower low mobility distance on day 1 after injury than in sham-injured rats $(\mathrm{P}<0.05)$. There was no main effect of sex on any of these parameters. There was an interaction of sex with day after injury for bouts of low mobility $\left(\mathrm{F}_{4,200}=3.28, \mathrm{P}<0.05\right)$ such that females had fewer bouts than males on day 21 after injury $(\mathrm{P}<0.05)$. There were no other interactions of sex with injury for either parameter or with day after injury for low mobility distance.

The acute effects of TBI on day 1 after injury were further analyzed for effects on distance traveled, low mobility bouts, and low mobility distance across the 20-min observation period in 2-min time bins (Supplemental fig. 1). For distance traveled, there was a main effect only of time bin $\left(\mathrm{F}_{9,450}=89.60, \mathrm{P}<0.001\right)$, consistent with the habituation of the rats to the actometer chamber. Bouts of low mobility exhibited main effects of injury $\left(\mathrm{F}_{1,50}=29.31\right.$, $\mathrm{P}<0.001)$ and time bin $\left(\mathrm{F}_{9,450}=51.49, \mathrm{P}<0.001\right)$, and an interaction of injury with time bin $\left(\mathrm{F}_{9,450}=3.49, \mathrm{P}<0.001\right)$. Post hoc analysis indicated that although the number of low mob bouts increased across time bins in both TBI and sham-injured rats, the number of bouts of low mobility was lower in rats with TBI during time bins 2 through $10(\mathrm{P}<0.05)$, Low mobility distance exhibited main effects of injury $\left(\mathrm{F}_{1,50}=33.66, \mathrm{P}<0.001\right)$ and time bin $\left(\mathrm{F}_{9,450}=47.56, \mathrm{P}<0.001\right)$, and an interaction of injury with time bin $\left(\mathrm{F}_{9,450}=4.58, \mathrm{P}<0.001\right)$. Post hoc analysis indicated that low mobility distance increased across time bins in all 
groups, but the increase was smaller in rats with TBI than in sham-injured rats. There were no effects of sex, or interaction of sex with the other parameters.

Turning bias (fig. 4$)$ exhibited a significant main effect of $\operatorname{sex}\left(\mathrm{F}_{1,50}=6.96, \mathrm{P}<0.05\right)$ such that males exhibited a tendency to turn to the left, whereas females did not exhibit a significant turning bias. Turning bias also exhibited a significant main effect of injury $\left(\mathrm{F}_{1,50}=19.28\right.$, $\mathrm{P}<0.001$ ) such that rats with TBI exhibited greater tendency to turn towards the contralateral side compared to sham-injured rats, and an interaction of injury with day after injury $\left(\mathrm{F}_{4,200}=2.44, \mathrm{P}<0.05\right)$. There were no interactions of sex with injury, sex with day after injury, or sex with injury with day after injury. Post hoc analysis indicated that turning bias was greater in female rats with TBI on days 1 and $21(\mathrm{P}<0.05)$. A similar pattern was observed after TBI in male rats although the increase in turning bias on day 21 after injury was not quite significant $(\mathrm{P}=0.054)$.

3.2.4. Effects on body weight-Body weight exhibited main effects of sex $\left(\mathrm{F}_{1,50}=71.43, \mathrm{P}<0.001\right)$, day after injury $\left(\mathrm{F}_{4,200}=6892.67, \mathrm{P}<0.001\right)$, and an interaction of sex with day after injury $\left(\mathrm{F}_{4,200}=121.04, \mathrm{P}<0.001\right)$ by 3 -way ANOVA such that males were heavier than females and 14,21, and 28 days after injury ( $\mathrm{P}<0.001)$ (fig. 5). There was no main effect of injury, nor any other interactions. These results indicate that both male and female, and TBI and sham-injured rats maintained regular weight gain and growth throughout the study.

\section{Discussion}

\subsection{Identification of sensorimotor tests for use in juvenile rats}

This study assessed the suitability of several behavioral tests for the detection of sensorimotor deficits the day after TBI in 17-day old juvenile rats, as well as during the short-to-midterm recovery period. A number of changes in locomotor development occur during this period (PND 17 to PND 45). Although adult-like walking patterns begin to emerge around PND 15, substantial hindlimb coordination does not develop until approximately PND 20 (Altman and Sudarshan, 1975; Westerga and Gramsbergen, 1990). Visual function, another contributor to sensorimotor function, also changes substantially during this period of development. Pups do not open their eyes until about PND 14, and visual acuity does not fully mature until approximately PND 45 (Fagiolini et al., 1994). The immaturity of the motor and visual systems at PND 17 (and even earlier if the tests require pre-training), combined with the dramatic changes in neurodevelopment between PND 17 and adulthood and the rats' rapid growth, underscore the critical need to identify appropriate sensorimotor tests for use in the developing rat.

Several types of behavioral assessments have been used with juvenile rodent models of TBI. Most typically, the Morris water maze has been used to assess cognitive function after TBI in 17-day old rats (Adelson et al., 2000; Adelson et al., 1997; Appelberg et al., 2009; Fineman et al., 2000; Hickey et al., 2007; Huh et al., 2008; Ochalski et al., 2010; Prins and Hovda, 1998; Raghupathi and Huh, 2007). Motor and vestibular function have also been assessed using methods such as the beam balance, inclined plane, and grip tests (Adelson et al., 2000). These tests, however, have limited ability to detect sided deficits, which would result after a unilateral TBI.

Sensorimotor testing in adult rodent models of TBI and other neural injuries is common (for review see Fujimoto et al., 2004) and has been done using a variety of tests such as the grid walk, accelerating rotarod, gait analysis, beam walk, and the spontaneous forelimb elevation test. Although these tests assess the motor deficits of interest after TBI, the present data demonstrate that at least some of them proved unsuitable, or not feasible, for use with young 
juvenile rats. Notably, the rotarod, a well established test of motor function first used to describe motor deficits in adult rats after TBI by Hamm and colleagues (1994), proved to be unsuitable because of inadequate scalability of the instruments and because the youngest rats of interest in our studies were not developmentally capable of performing the test. The grid walk test, which has been used to detect limb deficits in adult and neonatal rat and adult mouse spinal cord injury models (Kunkel-Bagden et al., 1992; Pajoohesh-Ganji et al., 2010; Pitzer et al., 2010) and adult mouse TBI models (Baskin et al., 2003; Onyszchuk et al., 2007; Onyszchuk et al., 2008), could potentially be used with developing rats, but would require the fabrication of multiple appropriately-scaled apparatuses. Furthermore analysis of the grid walk video tapes was quite labor intensive. Likewise, automated gait analysis, which has been used to detect variances in gait after spinal cord injury (Ek et al., 2010; Springer et al., 2010), suffered from issues relating to development of the rats and experimental throughput. Thus, these tests were disfavored for use with the 17-day old juvenile rat TBI model.

In contrast, several tests proved appropriate and expedient for sensorimotor testing in juvenile rats. The spontaneous forelimb elevation test, beam walk, and measurement of motor activity using the force-plate actometer provided useful data in 17-day old rats. The spontaneous forelimb elevation test, which detects CNS injury-related forelimb deficits in multiple rodent models of neurologic injury (Baskin et al., 2003; Bretzner et al., 2008; Li et al., 2004; Schallert et al., 2000; Vandeputte et al., 2010), was easily modified to accommodate growing rats by using cylinders of varying sizes. Likewise the beam walk test, which detects hindlimb deficit after TBI and other neural injuries in adolescent and adult rats (e.g., Appelberg et al., 2009; Kalonia et al., 2010; Scafidi et al., 2010; Sgado et al., 2010; Wagner et al., 2007), proved achievable by rats as young as PND 16, thus allowing for the pre-training necessary for this test prior to injury on PND 17. The force-plate actometer, which has not been used in TBI but has been used to detect altered motor function in a mouse model of Huntington's disease (Fowler et al., 2009), was suitable for all ages and sizes of rats. In agreement with previous studies (e.g., Levant et al., 2010; Spear and Brake, 1983), distance traveled in the actometer decreased with age. Although it is not certain whether this change in activity reflects neurodevelopmental maturation of the rats, the change in the size relationship between the rat and the actometer chamber, or both, this procedure is clearly capable of assessing behavior in rats of all the ages of interest in this study. In contrast to the tests previously used in juvenile TBI (see above), the spontaneous forelimb elevation, beam walk, and force-plate actometer tests have the additional advantages of detecting deficits preferentially affecting one side of the body that result from a unilateral CCI injury. In addition, combined use of the spontaneous forelimb elevation and beam walk tests enables separate resolution of fore- and hind-limb deficits. Furthermore, the tests have sufficient throughput capabilities to render them suitable for testing the number of subjects used in this study.

\subsection{Effects of $T B I$ on sensorimotor function in the juvenile rat model}

All tests deemed suitable for use with 16-to 45-day old rats detected sensorimotor deficits after TBI. While these deficits were likely due to the effect of the CCI-injury, the present experimental design does not allow for the differentiation of the contributions of the craniotomy and the CCI to this effect.

Forelimb deficits assessed by the spontaneous forelimb elevation test were first observed on the day after injury and persisted for at least 28 days after injury (fig. 2). The persistent deficit in forelimb function after TBI is likely indicative of poor long-term outcome. The persistence of this deficit also suggests that this test may be useful in assessing interventions to improve outcomes of TBI. The detection of both initial and persistent functional impairment may also prove useful in discerning the mitigation of the various pathological 
processes initiated by TBI, such as acute neuroinflammation or blood brain barrier disruption, which resolve relatively quickly after injury (Adelson et al., 1998; Bolton and Perry, 1998; Gaetz, 2004; Walker et al., 2009), as well as long-term sequelae of TBI such as apoptosis and glial scar formation (Walker et al., 2009).

The beam walk also detected both acute functional impairment and persistent deficits after TBI (fig. 1A), indicating that this test should be useful in assessing therapeutic interventions for TBI. The improvement in percent foot slips in this test between days 1 and 14 after injury was greater in the rats with TBI than in sham-injured rats. This indicates some recovery of function after injury in addition to maturation-associated improvements in limb coordination and/or the effects of practice with repeated testing that were also observed in the sham-injured group. The speed with which the rats traversed the beam also revealed effects of TBI, but only on day 1 after injury (fig. 1B). Thus, traverse speed may be useful for comparing the initial effects of injuries of varying severity or the effects of interventions that affect the initial inflammatory response.

The sensorimotor functions assessed by force-plate actometry also clearly detected effects of TBI. Rats with TBI exhibited an increased turning bias toward the left, away from the injured hemisphere (fig. 4), consistent with the fore- and hind-limb deficits observed in the spontaneous forelimb elevation and beam walk tests. This effect was observed one day after injury, and also at some of the later time points. However, the detection of TBI-induced turning bias was not entirely consistent over time. Accordingly, this parameter should prove useful in detecting acute effects of TBI, though additional evaluation is required to determine its utility for the assessment of recovery after TBI. In addition, bouts of low mobility and low mobility distance, which assess the number of instances that the rats spend time moving confined within a small area ( $20 \mathrm{~mm}$ radius) and the amount of movement within the 20-mm radius, were altered after TBI, but this effect was observed only on the day after injury. Thus, these low mobility parameters may be most useful for assessing the acute affects of TBI, or may prove effective for detecting the effects of factors that may worsen TBI outcomes. Interestingly, rats with TBI exhibited fewer bouts of low mobility (fig. 3B) and decreased low mobility distance (fig. 3C) indicating that they make fewer small movements when not locomoting than sham-injured rats. Despite making fewer small movements, analysis of distance traveled, bouts of low mobility, and low mobility distance across the observation period on day 1 after injury indicated that the pattern of behavior across the test session was generally similar between TBI and sham-injured rats (Supplemental fig. 1). The low mobility parameters are typically used as an index of stereotyped behavior (Fowler et al., 2001), but can also be used to measure other types of movements such as grooming. It is likely that the observed decrease in low mobility activity represents a transient decrease in grooming, which has been reported previously in adult rats with contusion injuries (Grossman et al., 2011).

\subsection{Sex difference in response to TBI in juvenile rats}

Sex differences in response to TBI are found in both humans and in adult rodents. Some studies suggest that females have less-adverse responses to TBI than do males, most likely due to the neuroprotective effects of estrogen and progesterone (Roof and Hall, 2000; Siegel et al., 2010), which decrease intracranial pressure and cerebral perfusion pressure after TBI (Shahrokhi et al., 2010), although poorer outcomes in women of childbearing age have also been reported (Bazarian et al., 2010). In addition to these effects attributed to sex hormones, sex differences exist prior to puberty as a result of genes encoded on the sex chromosomes that have sex-specific effects on the brain, selective gene inactivation, and sex-biased expression of genes expressed on other chromosomes (Arnold, 2009; Mank, 2009). Consistent with these pre-pubertal differences, some sex differences in response to neural injury have been reported in juvenile rodents. For example, in a neonatal hypoxia-ischemia 
model, females exhibited a caspase- 3 mediated mechanism of apoptosis whereas males exhibited a caspase-independent mechanism of cell death (Zhu et al., 2006). These findings suggest that both adult and juvenile rodents exhibit sex differences in cellular response to neural injury; however, the full extent of differences prior to puberty including differences in sensorimotor function after TBI is unknown.

Because of the potential for sex differences in the juvenile rat model, the effects of sex on sensorimotor response to TBI were assessed. In this study, male and female juvenile rats exhibited generally similar behavior in the sensorimotor tests irrespective of injury, with two notable exceptions. First, females had fewer low mobility bouts at the 21 day time point after injury (PND 38) (fig. 3B), which may be attributable to puberty-associated changes. This general similarity in activity between the sexes is consistent with previous observations that locomotor activity is similar in male and female rats until late adolescence (PND 52-54) when females begin to exhibit higher levels of activity that varies with the estrous cycle (Finger, 1969; Lynn and Brown, 2009). In addition, a main effect of sex was observed for turning bias (fig. 4), where males had greater baseline turning bias than females. Despite this sex difference in baseline turning bias, both male and female rats responded similarly after TBI with respect to turning bias, as well as in all of the other tests used in this study. These observations support the hypothesis that the sex differences in TBI outcomes observed in adults are due to post-pubertal secretion of sex hormones.

\subsection{Conclusion}

We have identified sensorimotor behavioral tests for use in assessing effects shortly after injury and during the short-to midterm recovery period in a 17-day old rat model of TBI. The beam walk and the spontaneous forelimb elevation tests are easily scalable for growth over time, have a relatively high throughput, are appropriate for rats of any developmental stage, and require limited or no pre-training. Both tests detected acute and persistent functional deficits indicating that they may be useful in identifying interventions to improve outcomes after TBI. The force-plate actometer also detected acute functional deficits after TBI; however the utility of this test and its ability to detect long-term deficits require further evaluation. The lack of sex differences in outcomes in juvenile rats after TBI suggests that outcomes in pre-pubertal males and females may be similar, at least with respect to sensorimotor function.

\section{Supplementary Material}

Refer to Web version on PubMed Central for supplementary material.

\section{Acknowledgments}

Supported by NIH HD059939 (BL), HD02528 (BL, NEJB, SCF), RR016475 (BL), ES007079 (KLR), the University of Kansas Medical Center Biomedical Research Training Program (KLR), and the ASPET SURF program (KMK).

\section{References}

Adelson PD. Animal models of traumatic brain injury in the immature: a review. Exp Toxicol Pathol. 1999; 51:130-6. [PubMed: 10192581]

Adelson PD, Dixon CE, Kochanek PM. Long-term dysfunction following diffuse traumatic brain injury in the immature rat. J Neurotrauma. 2000; 17:273-82. [PubMed: 10776912]

Adelson PD, Dixon CE, Robichaud P, Kochanek PM. Motor and cognitive functional deficits following diffuse traumatic brain injury in the immature rat. J Neurotrauma. 1997; 14:99-108. [PubMed: 9069441] 
Adelson PD, Whalen MJ, Kochanek PM, Robichaud P, Carlos TM. Blood brain barrier permeability and acute inflammation in two models of traumatic brain injury in the immature rat: a preliminary report. Acta Neurochir Suppl. 1998; 71:104-6. [PubMed: 9779157]

Altman J, Sudarshan K. Postnatal development of locomotion in the laboratory rat. Anim Behav. 1975; 23:896-920. [PubMed: 1200422]

Appelberg KS, Hovda DA, Prins ML. The effects of a ketogenic diet on behavioral outcome after controlled cortical impact injury in the juvenile and adult rat. J Neurotrauma. 2009; 26:497-506. [PubMed: 19231995]

Arnold AP. The organizational-activational hypothesis as the foundation for a unified theory of sexual differentiation of all mammalian tissues. Horm Behav. 2009; 55:570-8. [PubMed: 19446073]

Baskin YK, Dietrich WD, Green EJ. Two effective behavioral tasks for evaluating sensorimotor dysfunction following traumatic brain injury in mice. J Neurosci Methods. 2003; 129:87-93. [PubMed: 12951236]

Bazarian JJ, Blyth B, Mookerjee S, He H, McDermott MP. Sex differences in outcome after mild traumatic brain injury. J Neurotrauma. 2010; 27:527-39. [PubMed: 19938945]

Bilgen M. A new device for experimental modeling of central nervous system injuries. Neurorehabil Neural Repair. 2005; 19:219-26. [PubMed: 16093412]

Bolton SJ, Perry VH. Differential blood-brain barrier breakdown and leucocyte recruitment following excitotoxic lesions in juvenile and adult rats. Exp Neurol. 1998; 154:231-40. [PubMed: 9875284]

Bretzner F, Liu J, Currie E, Roskams AJ, Tetzlaff W. Undesired effects of a combinatorial treatment for spinal cord injury--transplantation of olfactory ensheathing cells and BDNF infusion to the red nucleus. Eur J Neurosci. 2008; 28:1795-807. [PubMed: 18973595]

Chen SF, Hsu CW, Huang WH, Wang JY. Post-injury baicalein improves histological and functional outcomes and reduces inflammatory cytokines after experimental traumatic brain injury. $\mathrm{Br} \mathrm{J}$ Pharmacol. 2008; 155:1279-96. [PubMed: 18776918]

Cole JT, Yarnell A, Kean WS, Gold E, Lewis B, Ren M, McMullen DC, Jacobowitz DM, Pollard HB, O’Neill JT, Grunberg NE, Dalgard CL, Frank JA, Watson WD. Craniotomy: true sham for traumatic brain injury, or a sham of a sham? J Neurotrauma. 2011; 28:359-69. [PubMed: 21190398]

Davis AS, Dean RS. Assessing sensory-motor deficits in pediatric traumatic brain injury. Appl Neuropsychol. 2010; 17:104-9. [PubMed: 20467950]

Ek CJ, Habgood MD, Callaway JK, Dennis R, Dziegielewska KM, Johansson PA, Potter A, Wheaton $\mathrm{B}$, Saunders NR. Spatio-temporal progression of grey and white matter damage following contusion injury in rat spinal cord. PLoS One. 2010; 5:e12021. [PubMed: 20711496]

Fagiolini M, Pizzorusso T, Berardi N, Domenici L, Maffei L. Functional postnatal development of the rat primary visual cortex and the role of visual experience: dark rearing and monocular deprivation. Vision Res. 1994; 34:709-20. [PubMed: 8160387]

Faul, M.; Xu, L.; Wald, M.; Coronado, V. Traumatic Brain Injury in the United States: Emergency Department visits, Hospitalizations and Deaths 2002-2006. Atlanta (GA): Centers for Disease Control and Prevention, National Center for Injury Prevention and Control; 2010.

Fineman I, Giza CC, Nahed BV, Lee SM, Hovda DA. Inhibition of neocortical plasticity during development by a moderate concussive brain injury. J Neurotrauma. 2000; 17:739-49. [PubMed: 11011814]

Finger FW. Estrus and general activity in the rat. J Comp Physiol Psychol. 1969; 68:461-6. [PubMed: 5817704]

Fowler SC, Birkestrand BR, Chen R, Moss SJ, Vorontsova E, Wang G, Zarcone TJ. A force-plate actometer for quantitating rodent behaviors: illustrative data on locomotion, rotation, spatial patterning, stereotypies, and tremor. J Neurosci Methods. 2001; 107:107-24. [PubMed: 11389948]

Fowler SC, Miller BR, Gaither TW, Johnson MA, Rebec GV. Force-plate quantification of progressive behavioral deficits in the R6/2 mouse model of Huntington's disease. Behav Brain Res. 2009; 202:130-7. [PubMed: 19447289]

Gaetz M. The neurophysiology of brain injury. Clin Neurophysiol. 2004; 115:4-18. [PubMed: 14706464] 
Ginstfeldt T, Emanuelson I. An overview of attention deficits after paediatric traumatic brain injury. Brain Inj. 2010; 24:1123-34. [PubMed: 20715886]

Giza CC, Prins ML. Is being plastic fantastic? Mechanisms of altered plasticity after developmental traumatic brain injury. Dev Neurosci. 2006; 28:364-79. [PubMed: 16943660]

Grossman KJ, Goss CW, Stein DG. Sickness behaviors following medial frontal cortical contusions in male rats. Behav Brain Res. 2011; 217:202-8. [PubMed: 20933021]

Hamm RJ. Neurobehavioral assessment of outcome following traumatic brain injury in rats: an evaluation of selected measures. J Neurotrauma. 2001; 18:1207-16. [PubMed: 11721739]

Hamm RJ, Pike BR, O'Dell DM, Lyeth BG, Jenkins LW. The rotarod test: an evaluation of its effectiveness in assessing motor deficits following traumatic brain injury. J Neurotrauma. 1994; 11:187-96. [PubMed: 7932797]

Hickey RW, Adelson PD, Johnnides MJ, Davis DS, Yu Z, Rose ME, Chang YF, Graham SH. Cyclooxygenase-2 activity following traumatic brain injury in the developing rat. Pediatr Res. 2007; 62:271-6. [PubMed: 17622965]

Horton AM Jr, Soper HV, Reynolds CR. Executive functions in children with traumatic brain injury. Appl Neuropsychol. 2010; 17:99-103. [PubMed: 20467949]

Huh JW, Widing AG, Raghupathi R. Midline brain injury in the immature rat induces sustained cognitive deficits, bihemispheric axonal injury and neurodegeneration. Exp Neurol. 2008; 213:8492. [PubMed: 18599043]

Kalonia H, Kumar P, Kumar A. Licofelone attenuates quinolinic acid induced Huntington like symptoms: Possible behavioral, biochemical and cellular alterations. Prog Neuropsychopharmacol Biol Psychiatry. 2010

Kunkel-Bagden E, Dai HN, Bregman BS. Recovery of function after spinal cord hemisection in newborn and adult rats: differential effects on reflex and locomotor function. Exp Neurol. 1992; 116:40-51. [PubMed: 1559563]

Lajiness-O’Neill R, Erdodi L, Bigler ED. Memory and learning in pediatric traumatic brain injury: a review and examination of moderators of outcome. Appl Neuropsychol. 2010; 17:83-92. [PubMed: 20467947]

Levant B, Zarcone TJ, Fowler SC. Developmental effects of dietary n-3 fatty acids on activity and response to novelty. Physiol Behav. 2010; 101:176-83. [PubMed: 20457171]

Li X, Blizzard KK, Zeng Z, DeVries AC, Hurn PD, McCullough LD. Chronic behavioral testing after focal ischemia in the mouse: functional recovery and the effects of gender. Exp Neurol. 2004; 187:94-104. [PubMed: 15081592]

Luerssen TG, Klauber MR, Marshall LF. Outcome from head injury related to patient's age. A longitudinal prospective study of adult and pediatric head injury. J Neurosurg. 1988; 68:409-16. [PubMed: 3343613]

Lynn DA, Brown GR. The ontogeny of exploratory behavior in male and female adolescent rats (Rattus norvegicus). Dev Psychobiol. 2009; 51:513-20. [PubMed: 19582791]

Mank JE. Sex chromosomes and the evolution of sexual dimorphism: lessons from the genome. Am Nat. 2009; 173:141-50. [PubMed: 20374139]

Narayana PA, Grill RJ, Chacko T, Vang R. Endogenous recovery of injured spinal cord: longitudinal in vivo magnetic resonance imaging. J Neurosci Res. 2004; 78:749-59. [PubMed: 15499591]

National Institute of Neurologic Disorders and Stroke. Traumatic Brain Injury: Hope Through Research. National Institutes of Health; Bethesda, MD: 2002. http://www.ninds.nih.gov/disorders/tbi/detail_tbi.htm

Noggle CA, Pierson EE. Psychosocial and behavioral functioning following pediatric TBI: presentation, assessment, and intervention. Appl Neuropsychol. 2010; 17:110-5. [PubMed: 20467951]

Ochalski PG, Fellows-Mayle W, Hsieh LB, Srinivas R, Okonkwo DO, Dixon CE, Adelson PD. Flumazenil administration attenuates cognitive impairment in immature rats after controlled cortical impact. J Neurotrauma. 2010; 27:647-51. [PubMed: 19929186]

Onyszchuk G, Al-Hafez B, He YY, Bilgen M, Berman NE, Brooks WM. A mouse model of sensorimotor controlled cortical impact: characterization using longitudinal magnetic resonance 
imaging, behavioral assessments and histology. J Neurosci Methods. 2007; 160:187-96. [PubMed: 17049995]

Onyszchuk G, He YY, Berman NE, Brooks WM. Detrimental effects of aging on outcome from traumatic brain injury: a behavioral, magnetic resonance imaging, and histological study in mice. J Neurotrauma. 2008; 25:153-71. [PubMed: 18260798]

Pajoohesh-Ganji A, Byrnes KR, Fatemi G, Faden AI. A combined scoring method to assess behavioral recovery after mouse spinal cord injury. Neurosci Res. 2010; 67:117-25. [PubMed: 20188770]

Paxinos, G.; Watson, C. The Rat Brain in Stereotaxic Coordinates. Academic Press, Inc; San Diego: 1986.

Pitzer C, Klussmann S, Kruger C, Letellier E, Plaas C, Dittgen T, Kirsch F, Stieltjes B, Weber D, Laage R, Martin-Villalba A, Schneider A. The hematopoietic factor granulocyte-colony stimulating factor improves outcome in experimental spinal cord injury. J Neurochem. 2010; 113:930-42. [PubMed: 20202082]

Prins ML, Hovda DA. Developing experimental models to address traumatic brain injury in children. J Neurotrauma. 2003; 20:123-37. [PubMed: 12675967]

Prins ML, Hovda DA. Traumatic brain injury in the developing rat: effects of maturation on Morris water maze acquisition. J Neurotrauma. 1998; 15:799-811. [PubMed: 9814636]

Raghupathi R, Huh JW. Diffuse brain injury in the immature rat: evidence for an age-at-injury effect on cognitive function and histopathologic damage. J Neurotrauma. 2007; 24:1596-608. [PubMed: 17970623]

Roof RL, Hall ED. Gender differences in acute CNS trauma and stroke: neuroprotective effects of estrogen and progesterone. J Neurotrauma. 2000; 17:367-88. [PubMed: 10833057]

Scafidi S, Racz J, Hazelton J, McKenna MC, Fiskum G. Neuroprotection by acetyl-L-carnitine after traumatic injury to the immature rat brain. Dev Neurosci. 2010; 32:480-7. [PubMed: 21228558]

Schallert T, Fleming SM, Leasure JL, Tillerson JL, Bland ST. CNS plasticity and assessment of forelimb sensorimotor outcome in unilateral rat models of stroke, cortical ablation, parkinsonism and spinal cord injury. Neuropharmacology. 2000; 39:777-87. [PubMed: 10699444]

Sgado P, Viaggi C, Pinna A, Marrone C, Vaglini F, Pontis S, Mercuri NB, Morelli M, Corsini GU. Behavioral, Neurochemical, and Electrophysiological Changes in an Early Spontaneous Mouse Model of Nigrostriatal Degeneration. Neurotox Res. 2010

Shahrokhi N, Khaksari M, Soltani Z, Mahmoodi M, Nakhaee N. Effect of sex steroid hormones on brain edema, intracranial pressure, and neurologic outcomes after traumatic brain injury. Can $\mathrm{J}$ Physiol Pharmacol. 2010; 88:414-21. [PubMed: 20555409]

Sherwood, NM.; Timiras, PS. A Stereotaxic Atlas of the Developing Rat Brain. University of California Press, Ltd; Berkeley and Los Angeles: 1970.

Siegel C, Turtzo C, McCullough LD. Sex differences in cerebral ischemia: possible molecular mechanisms. J Neurosci Res. 2010; 88:2765-74. [PubMed: 20698025]

Spear LP, Brake SC. Periadolescence: age-dependent behavior and psychopharmacological responsivity in rats. Dev Psychobiol. 1983; 16:83-109. [PubMed: 6339302]

Springer JE, Rao RR, Lim HR, Cho SI, Moon GJ, Lee HY, Park EJ, Noh JS, Gwag BJ. The functional and neuroprotective actions of Neu2000, a dual-acting pharmacological agent, in the treatment of acute spinal cord injury. J Neurotrauma. 2010; 27:139-49. [PubMed: 19772458]

Sullivan JR, Riccio CA. Language functioning and deficits following pediatric traumatic brain injury. Appl Neuropsychol. 2010; 17:93-8. [PubMed: 20467948]

Vandeputte C, Taymans JM, Casteels C, Coun F, Ni Y, Van Laere K, Baekelandt V. Automated quantitative gait analysis in animal models of movement disorders. BMC Neurosci. 2010; 11:92. [PubMed: 20691122]

Wagner AK, Postal BA, Darrah SD, Chen X, Khan AS. Deficits in novelty exploration after controlled cortical impact. J Neurotrauma. 2007; 24:1308-20. [PubMed: 17711392]

Walker PA, Harting MT, Baumgartner JE, Fletcher S, Strobel N, Cox CS Jr. Modern approaches to pediatric brain injury therapy. J Trauma. 2009; 67:S120-7. [PubMed: 19667844]

Westerga J, Gramsbergen A. The development of locomotion in the rat. Brain Res Dev Brain Res. 1990; 57:163-74. 
Ylvisaker M, Todis B, Glang A, Urbanczyk B, Franklin C, DePompei R, Feeney T, Maxwell NM, Pearson S, Tyler JS. Educating students with TBI: themes and recommendations. J Head Trauma Rehabil. 2001; 16:76-93. [PubMed: 11277852]

Zhu C, Xu F, Wang X, Shibata M, Uchiyama Y, Blomgren K, Hagberg H. Different apoptotic mechanisms are activated in male and female brains after neonatal hypoxia-ischaemia. $\mathrm{J}$ Neurochem. 2006; 96:1016-27. [PubMed: 16412092] 


\section{Highlights}

- Six behavioral tests were evaluated for use with 17-day old rats.

- The spontaneous forelimb elevation test detected forelimb deficits after TBI.

- The beam walk test detected hindlimb deficits after TBI.

- The force-plate actometer detected a change in turning bias after TBI.

- Juvenile male and female rats exhibit similar sensorimotor deficits following TBI. 

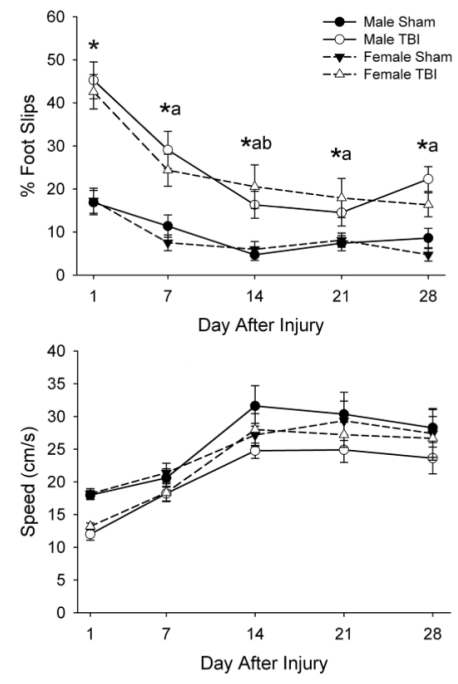

Fig. 1. Effects of TBI in male and female juvenile rats in the beam walk test on percent foot slips (A) and traverse speed (B)

Data are presented as the group means \pm SEM ( $n=12-15 /$ group). Traverse speed exhibited only main effects of injury $(\mathrm{P}<0.05)$ and day after injury $(\mathrm{P}<0.01)$. *TBI different from Sham, same day and for males and females combined $(\mathrm{P}<0.05)$. ${ }^{\mathrm{D}}$ Different from Day 1 , same injury and for males and females combined $(\mathrm{P}<0.01)$. ${ }^{\mathrm{b}}$ Different from Day 7 , same injury and for males and females combined $(\mathrm{P}<0.05)$ by ANOVA and Fisher's LSD test. 


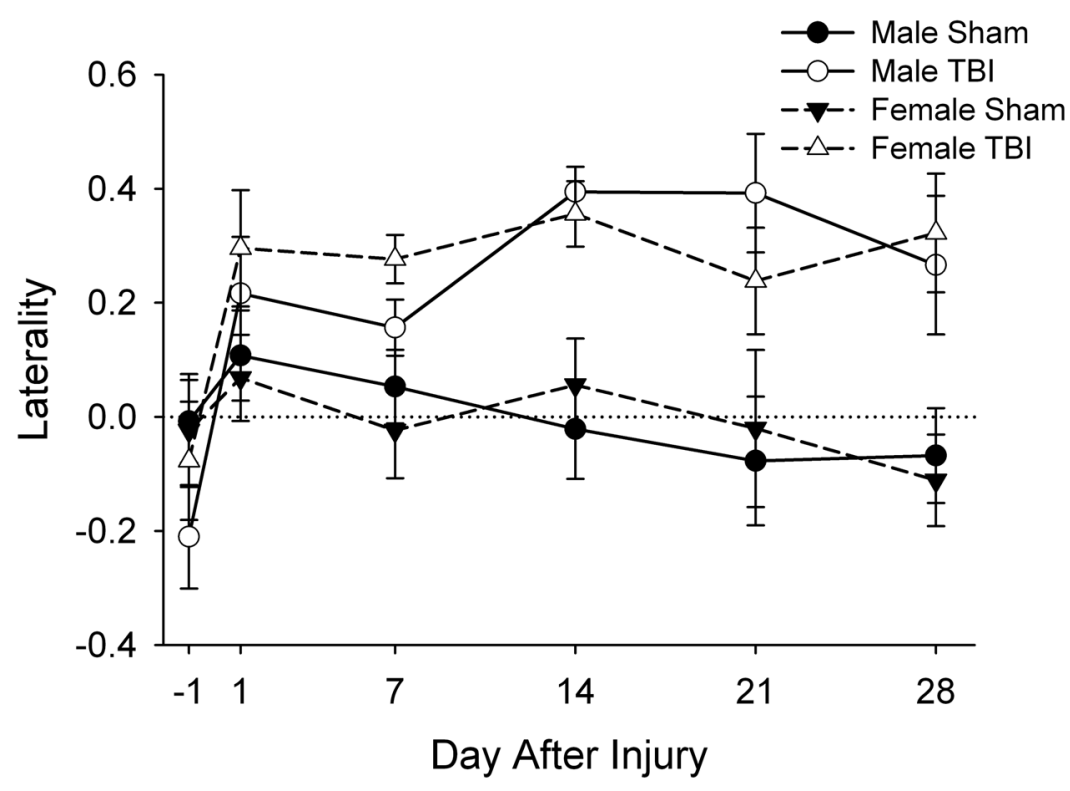

Fig. 2. Effects of TBI in male and female juvenile rats in the spontaneous forelimb elevation test Data are presented as the group means \pm SEM ( $n=12-15 /$ group). No differences in laterality were detected prior to injury. After injury, three-way ANOVA revealed only a significant main effect of injury $(\mathrm{P}<0.001)$ indicating a greater laterality in rats with $\mathrm{TBI}$ rats at all time points. 

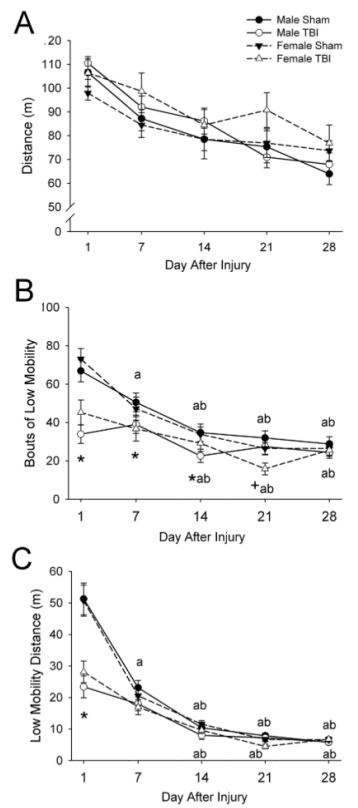

Fig. 3. Effects of TBI in male and female juvenile rats on distance traveled (A), bouts of low mobility (B), and low mobility distance $(C)$ assessed using the force-plate actometer Data are presented as the group means \pm SEM ( $n=12-15$ /group) for the entire 20-min observation period on days $1,7,14,21$, and 28 after injury. Low mobility bouts are defined as $\geq 10 \mathrm{sec}$ spent within a 20 -mm radius. Low mobility distance is the distance traveled during bouts of low mobility. Distance traveled (A) exhibited only a main effect of day after injury $(\mathrm{P}<0.001)$. *TBI different from Sham, same day and for males and females combined

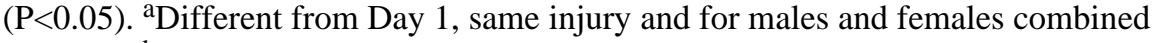
$(\mathrm{P}<0.05) .{ }^{\mathrm{b}}$ Different from Day 7 , same injury and for males and females combined $(\mathrm{P}<0.05) .{ }^{+}$Female different from male, same day and for TBI and sham-injured combined $(\mathrm{P}<0.05)$ by ANOVA and Fisher's LSD test. 

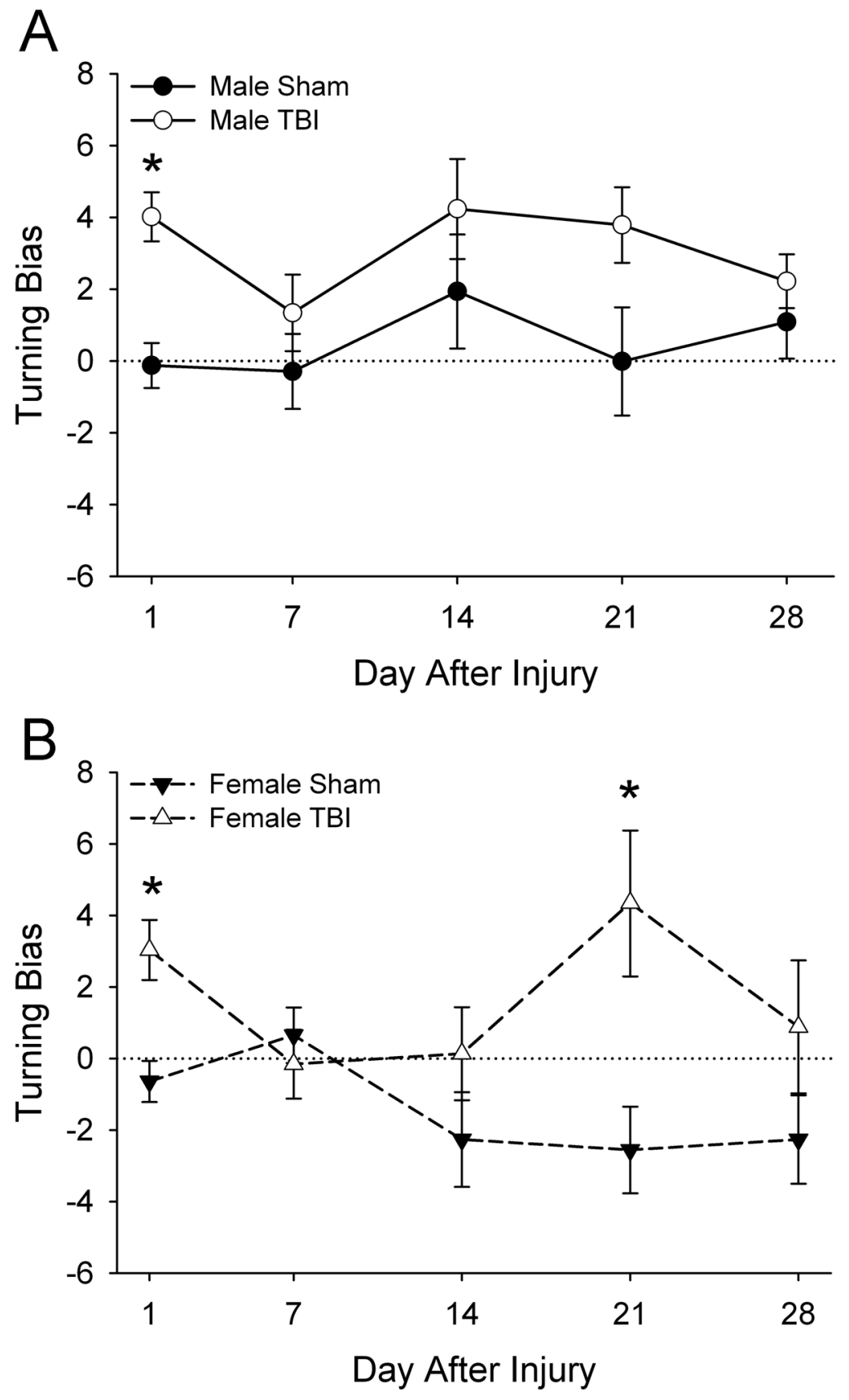

Fig. 4. Effects of TBI in male and female juvenile rats on turning bias assessed using the forceplate actometer

Data are presented as the group means \pm SEM ( $n=12-15 /$ group). Turning bias exhibited a significant main effect of sex $(\mathrm{P}<0.05)$ such that males $(\mathrm{A})$ males exhibited a tendency to turn to the left, whereas females (B) did not exhibit a significant turning bias. *TBI different from sham-injured $(\mathrm{P}<0.05)$ by ANOVA and Fisher's LSD test. 


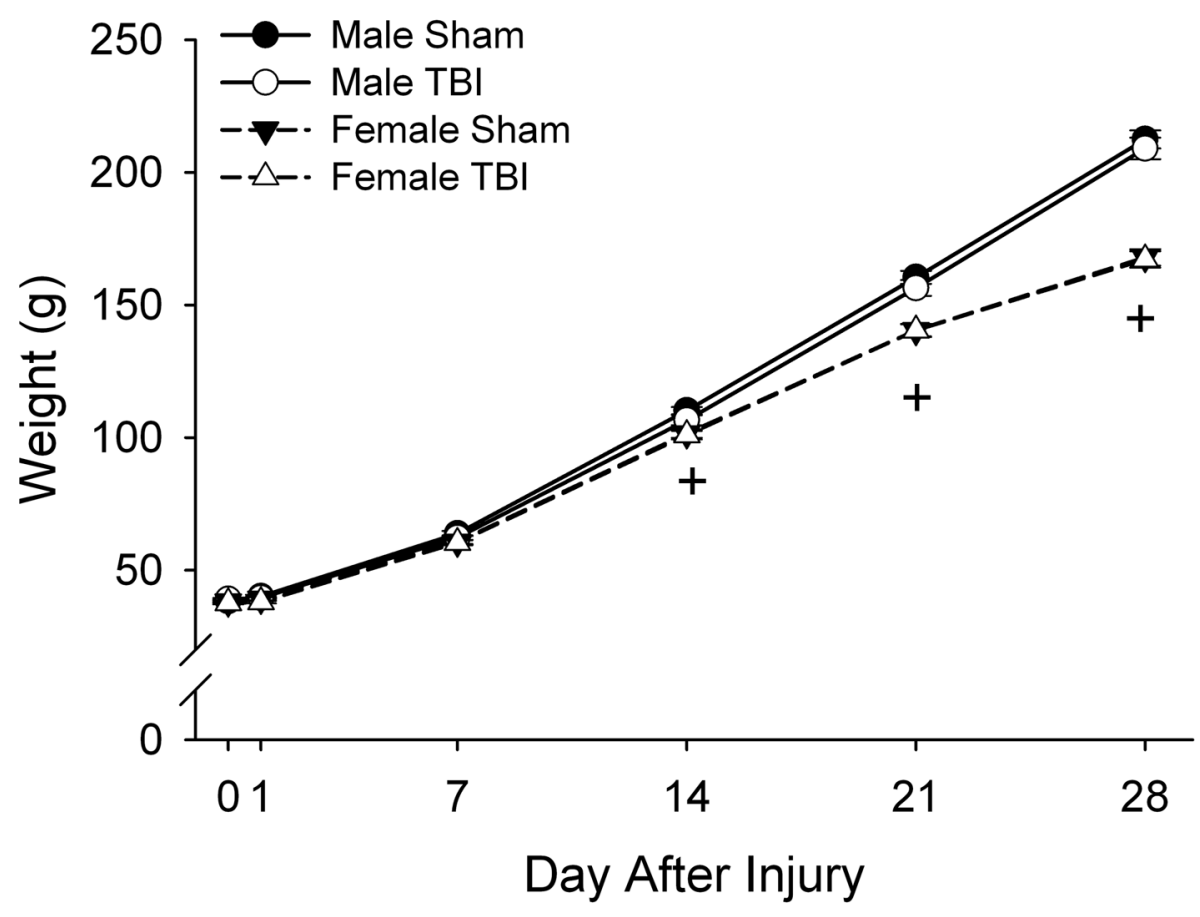

Fig. 5. Effects of TBI in male and female juvenile rats on body weight

Data are presented as the group means \pm SEM ( $n=12-15$ /group). Error bars that are not visible are smaller than the symbols. There were no significant differences in weight as a result of TBI. ${ }^{+}$Female different from male for TBI and sham-injured combined $(\mathrm{P}<0.001)$ by ANOVA and Fisher's LSD test. 


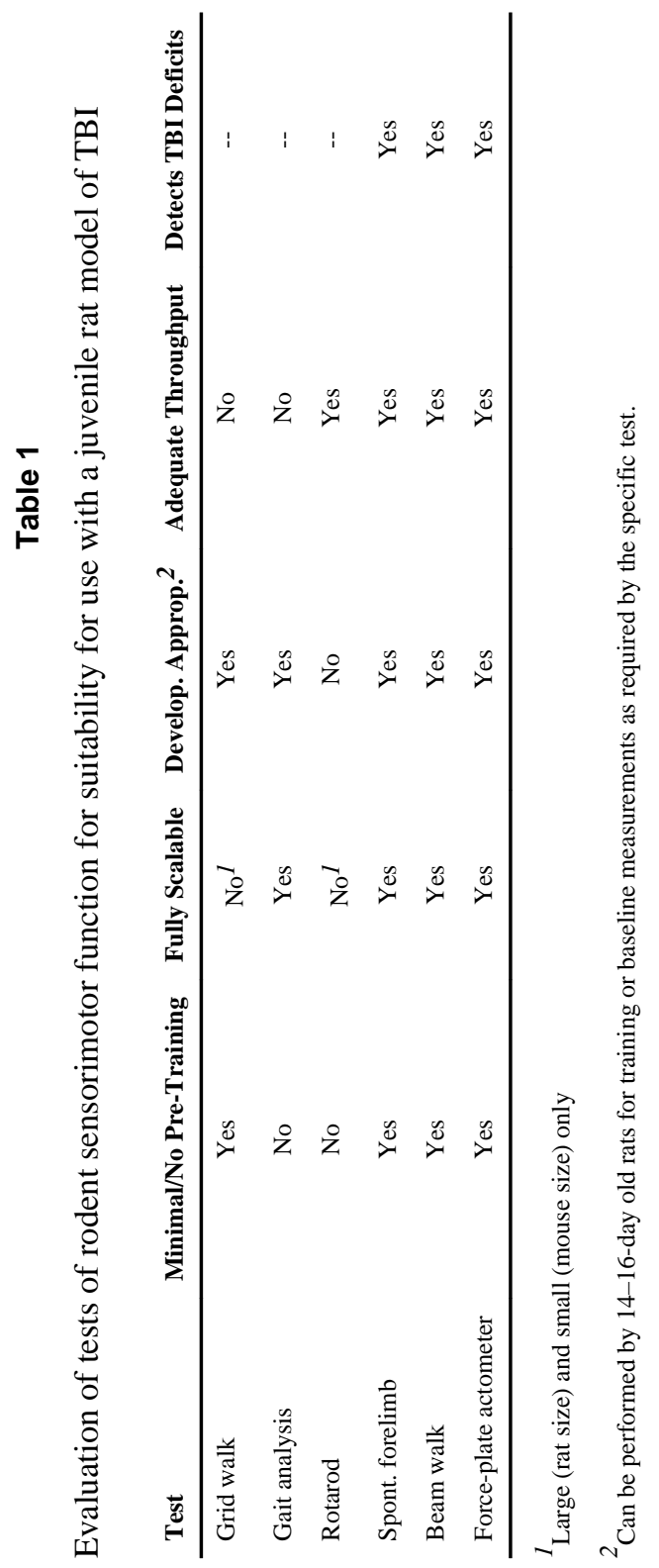

